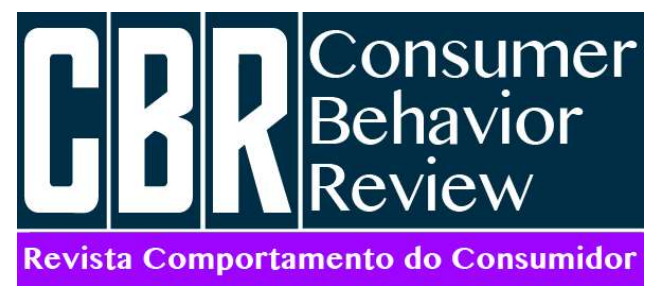

ISSN: 2526-7884

Editor: Prof. Dr. Marconi Freitas da Costa

E-mail: cbr@ufpe.br
Andreoli, T. P., Santos, S. F. O., Rodrigues, A. P. F., \& Silva, T. C. (2021). Influência dos Selos Verdes no Comportamento do Consumidor. Consumer Behavior Review, 5(1), 128-139.

\title{
INFLUÊNCIA DOS SELOS VERDES NO COMPORTAMENTO DO CONSUMIDOR
}

\author{
Influence of Green Stamps on Consumer Behavior
}

\author{
Tais Pasquotto Andreoli ${ }^{1}$ \\ ORCID: http://orcid.org/0000-0002-9173-9294 \\ E-mail: tais_pa@hotmail.com \\ Suelen Francine Oliveira Santos ${ }^{2}$ \\ ORCID: http://orcid.org/0000-0002-7528-9887 \\ E-mail: suelen.santos@hotmail.com \\ Ana Paula Frias Rodrigues ${ }^{2}$ \\ ORCID: http://orcid.org/0000-0001-7945-3720 \\ E-mail: anapaula.r@hotmail.com \\ Tatiana Carneiro Silva² \\ ORCID: http://orcid.org/0000-0002-0100-3372 \\ E-mail: tatiana.carneiro@hotmail.com
}

${ }^{1}$ Escola Paulista de Política, Economia e Negócios, Universidade Federal de São Paulo, Osasco, Brasil ${ }^{2}$ Faculdade Anhanguera Votorantim, São Paulo, Brasil

\begin{abstract}
Resumo
0 trabalho teve como objetivo analisar a influência da prática de selos verdes no comportamento dos consumidores. Procedeuse, inicialmente, a uma revisão da literatura, focando na discussão acerca do marketing societal, sua origem e evolução, discorrendo também sobre o marketing verde, seu conceito e sua importância, adentrando-se na temática da prática de selos verdes. Tendo a literatura
\end{abstract}

\begin{abstract}
The objective of this study was to analyze the influence of the practice of green stamps on consumer behavior. Initially, a review of the literature was carried out, focusing on the discussion about societal marketing, its origin and evolution, also discussing green marketing, its concept and its importance, entering the theme of the practice of green stamps. Taking the literature as support, a
\end{abstract}


como suporte, adotou-se metodologicamente uma abordagem quantitativa, realizada por meio de dois levantamentos quantitativos (surveys), o primeiro que analisou três produtos com o mesmo selo verde exposto, em conjunto $(\mathrm{n}=316)$, e o segundo que os analisou isoladamente $\quad(n=69), \quad$ comparando-os posteriormente. Foi possível verificar certa ambiguidade dos respondentes acerca da prática de selos verdes, de um lado valorizando-a como diferencial competitivo, mas, de outro, reconhecendo a falta de percepção e preocupação dos consumidores sobre isso.

Palavras-chave: Marketing societal; Marketing verde; Selos verdes; Comportamento do consumidor. quantitative approach was adopted using two quantitative surveys, the first one to analyze three products with the same green stamp, together $(n=316)$, and the second with them separately $(n=69)$, comparing them later. It was possible to verify some ambiguity of the respondents about the practice of green stamps, on the one hand valuing it as a competitive differential, but, on the other, recognizing the lack of perception and concern of the consumers about it.

Keywords: Societal marketing; Green marketing; Green seals; Consumer behavior.

\section{INTRODUÇÃO}

Atualmente um dos temas mais importantes e com necessidade de urgência é a problemática social e ambiental, especialmente vinculada à atuação organizacional e seus potenciais impactos nos ambientes de atuação. Essa discussão se iniciou em meados de 1970, gradualmente ganhando repercussão, e atualmente é causa de preocupação global, tanto no nível da sociedade quanto no âmbito empresarial (Andreoli, Lima \& Minciotti, 2018).

Pesquisas mostram cenários bastante caóticos dia após dia quando o assunto é o meio ambiente. Os desastres naturais acontecem com grande frequência, a exposição da ausência dos recursos primários, a degradação excessiva do meio ambiente, a poluição, o consumo exagerado da população e a intervenção no meio social propendem causar prejuízos ao meio ambiente, afetando assim a existência humana (Guimarães, Viana \& Costa, 2015). Nesse ínterim, urge a necessidade de conscientização por parte da população, das organizações, dos consumidores e dos demais públicos de interesse (stakeholders).

Como consequência, as organizações buscam estratégias diferenciadas de atuação, que abarquem novos valores e adotem novos padrões relacionados aos meios social e ambiental, preocupando-se com os impactos de suas atuações. Trata-se da incorporação da consciência sustentável na prática organizacional e mercadológica, que não se resume a um mero apelo comercial, mas sim uma contínua estratégia de negócios. São exemplos expoentes dessa maior conscientização organizacional o marketing societal (Andreoli, Lima \& Minciotti, 2018) e o marketing verde (Andreoli, Lima \& Prearo, 2017).

Nesse sentido, o marketing societal reflete uma nova filosofia e prática das organizações perante os seus mercados de atuação, englobando todos os fatores que podem ocasionar danos ao indivíduo e também à sociedade (Andreoli, Lima \& Minciotti, 2018). Também nessa vertente, o marketing verde consiste em uma ideologia do marketing marcada pela preocupação com o meio ambiente, incorporando práticas mais responsáveis, com uma política de sustentabilidade com forte orientação para o futuro (Andreoli, Lima \& Prearo, 2017).

À luz do exposto, o trabalho teve como objetivo analisar a influência da prática de selos verdes no comportamento dos consumidores. Procedeu-se, inicialmente, a uma revisão da literatura, focando na discussão acerca do marketing societal, sua origem e evolução, discorrendo também sobre o marketing verde, seu conceito e sua importância, adentrando-se na temática da prática de selos verdes. Tendo a literatura como suporte, adotou-se metodologicamente uma abordagem quantitativa, realizada 
por meio de dois levantamentos quantitativos (surveys). 0 primeiro, mais geral, analisou três diferentes produtos que expõem o mesmo selo verde, obtendo 316 respostas. 0 segundo analisou-os isoladamente, comparando-os posteriormente, totalizando 69 respondentes.

Ao fazer isso, o trabalho busca averiguar a percepção dos consumidores acerca da adoção da prática de selos verdes por parte das organizações, principalmente em termos de reações após a exposição a um selo verde supostamente conhecido. Dessa forma, espera-se agregar evidências empíricas à compreensão dessa prática organizacional, que ainda carece de consenso (Andreoli, Lima \& Prearo, 2017). Além disso, o estudo do marketing verde, como um todo, ou de quaisquer das suas práticas específicas, mostram-se como importantes, de forma que a produção científica consiga acompanhar a movimentação atual do mercado (Mangini, Amaral, Conejero \& Pires, 2020).

\section{REFERENCIAL TEÓRICO}

0 referencial teórico se encontra dividido em três principais discussões: marketing societal, marketing verde e a prática dos selos verdes.

\section{Marketing Societal}

De maneira geral, até meados da década de 1970, impera sob o marketing uma perspectiva gerencial, com ênfase na busca de lucratividade, que deveria ser conquistada por meio da adaptação da produção e das ofertas de produtos que satisfizessem as necessidades e escolhas do consumidor. Apesar disso, ainda na década de 1970, ressaltam-se algumas publicações de diferentes pesquisadores no sentido de refletir acerca da atuação mercadológica, especialmente em relação aos seus possíveis impactos (Andreoli, Lima \& Minciotti, 2018).

Nesse sentido, Miranda e Arruda (2004) citam alguns marcos importantes. Primeiramente, temse Feldman, já em 1971, que advertiu acerca do consumo materialista, que seria impulsionado pelo marketing, alertando como isso poderia sobrecarregar os recursos da sociedade no longo prazo. Em seguida, em 1974, Takas ressaltou a desconsideração dos impactos sociais e ambientais da prática mercadológica, enfatizando, ainda, que o marketing tradicional estava fora de sintonia com o futuro. Tem-se também a Escola Sistêmica de Marketing, considerada grande influenciadora desse movimento, cujo foco residia principalmente nas consequências em termos de mudanças no meio ambiente.

Como resultado, começou uma revisão conceitual importante do marketing no meio acadêmico, que fez com que Kotler (1978), definisse, com pioneirismo, o marketing societal, que compreende a orientação para as necessidades dos clientes e consumidores, juntamente com o atendimento dos interesses dos demais stakeholders, em especial a sociedade. Dessa forma, o marketing societal surge com o intuito de atender às demandas desse novo contexto empresarial, que se relacionam principalmente à cobrança de uma postura mais responsável por parte das organizações, com valores éticos e sociais (Silva \& Minciotti, 2005; Silva, Minciotti \& Romeiro, 2011).

Assim, observa-se que o marketing societal possui duplo objetivo, o de atender ao mercado consumidor e gerar satisfação, em termos diretos, atingindo os objetivos organizacionais de desempenho e lucro, mas também de contribuir para um bem-estar social a longo prazo, garantindo a sustentabilidade da sociedade e, claro, do negócio (Schneider \& Luce, 2014). Ou seja, trata-se de um alinhamento entre os interesses financeiros aos sociais, mantendo o objetivo de lucro, mas com preocupação com a sociedade, em especial referente aos impactos das atividades organizacionais e, em particular, as mercadológicas (Silva \& Minciotti, 2005).

0 marketing societal reflete, assim, uma nova filosofia e prática das organizações perante os seus mercados de atuação, frente aos desafios comerciais atuais, resultantes da maior conscientização e criticidade do mercado e dos consumidores, que cobram práticas mais sustentáveis (Morais et al., 2005). Refere-se a um aprimoramento substancial do chamado marketing tradicional, superando o pensamento ortodoxo vigente até então, para englobar todos os fatores que poderiam ocasionar danos ao indivíduo e também à sociedade, tanto por causa da produção desenfreada quanto do consumo não consciente (Silva \& Minciotti, 2005; Bergel et al., 2015). 


\section{Marketing Verde}

Estimuladas pelas novas exigências do mercado as organizações começaram a desenvolver o marketing verde, acrescentando ações em diversas técnicas em marketing, no sentido de se colocar como ambientalmente responsável (Andreoli \& Batista, 2019). Dessa forma, o marketing verde é impulsionado principalmente como diferencial competitivo perante o mercado, especialmente frente os consumidores.

O Marketing Verde, também chamado de ecológico ou ambiental, surgiu das instituições não governamentais de proteção ao meio ambiente, como Greenpeace e WWF - Word Wildlife Fund, oriundas por volta da década de 1970 (Andreoli, Lima \& Prearo, 2017). Foi quanto a American Marketing Association (AMA) realizou um workshop com a finalidade de debater os danos do marketing no meio ambiente, tais como os referentes à poluição, ao esgotamento de energia e ao desgaste de recursos não renováveis.

$\mathrm{Na}$ atualidade, o marketing ambiental pode ser entendido como uma ideologia do marketing marcada pela preocupação com o meio ambiente (Andreoli, Crespo \& Minciotti, 2017). Ou seja, referese a uma nova conscientização acerca da prática organizacional e mercadológica, ponderando-se não só os fins lucrativos e seu atingimento, mas também os impactos inerentes a ela. Dessa forma, as organizações começam a incorporar práticas mais responsáveis, que tragam benefícios mercadológicos e organizacionais, mas com a minimização dos prejuízos ao meio ambiente. 0 marketing verde reflete, assim, uma nova filosofia de marketing, que busca a construção e manutenção de uma política de sustentabilidade com forte orientação para o futuro (Andreoli, Lima \& Prearo, 2017).

Nesse sentido, o propósito da comunicação do marketing verde é divulgar ao consumidor as práticas ecologicamente corretas, as que ponderam aspectos como preservação e diminuição da devastação/danificação ambiental, utilização de recursos de forma mais consciente, defesa de consumo sustentável, entre outros. Dessa forma, Guimarães, Viana e Costa (2015) defendem que essa prática de divulgação verde procura sensibilizar os consumidores acerca da problemática ambiental, a fim de que também eles entrem nessa causa, já que a responsabilidade é - sabidamente - de todos.

Como consequência, o marketing verde acaba contribuindo para uma que haja uma maior conscientização por parte do mercado, em especial dos consumidores, que passam a conhecer e se inteirar sobre toda essa problemática ambiental (Andreoli \& Batista, 2020). Isso possibilita, se não estimula, que eles passem a incorporar hábitos de compra e consumo mais ecologicamente corretos, bem como demandar e avaliar as ofertas com base nesses atributos (Andreoli, Lima \& Prearo, 2017).

Uma das práticas recorrentes de marketing verde relacionada à divulgação ao mercado se refere à adoção e utilização de selos verdes, temática a ser explorada a seguir.

\section{Selos Verdes}

Os rótulos ambientais ou selos verdes, como são popularmente conhecidos, presentes nas embalagens de produtos ou nas diversas formas de divulgação dele no mercado, têm como intuito evidenciar os atributos ambientais envolvidos na produção ou presentes no produto em si (Wells, 2006). Assim, a adoção e exibição de selos verdes servem para ressaltar a prática do marketing verde, atestando aos consumidores o compromisso ambiental da organização, em especial junto a um público mais consciente, que prioriza a sustentabilidade como diferencial de compra.

Dessa forma, as organizações passaram a conceber os selos verdes como importantes vantagens competitivas, capazes de destacarem seus produtos perante os concorrentes. Isso se mostra ainda mais importante ao lembrar que a conscientização e a preservação ambiental são de interesse de todos, estando diretamente entrelaçadas com a qualidade de vida das pessoas. Nesse sentido, são diversos aos autores que mencionam esse diferencial, inclusive como oportunidade estratégica, como é o caso de Campos et al (2013), Lopes e Pacagnan (2014) e Guimarães, Viana e Costa (2015).

De acordo com Araújo (2013), o selo verde não é apenas um símbolo ecológico na embalagem de um produto, mas o resultado de uma avaliação técnica criteriosa, na qual é elevado em conta aspectos pertinentes ao seu ciclo de vida, desde a compra da matéria-prima, seleção e utilização dos insumos e o processo produtivo (gastos de energia, emissão de poluentes, uso de água), até o momento dos descartes. Os selos verdes consistem, assim, em uma acreditação da qualidade ecológica e/ou 
socioambiental de determinado produto, concedida para organizações que comprovam que seus ciclos de vida são sustentáveis ambientalmente (Andreoli, Lima \& Prearo, 2017).

Tendo em vista essa dificuldade, algumas empresas optaram por se aproveitar das vantagens da prática da adoção e utilização de selos verdes junto ao mercado, mas sem o devido comprometimento de fato. Ou seja, começam a surgir casos de organizações que usam os selos verdes de forma duvidosa, indevida, ou mesmo enganosa, prática conceituada como greenwashing, ou lavagem verde, em português (Andreoli \& Batista, 2020).

\section{MÉTODO}

Para atender ao propósito do trabalho, enveredou-se por uma abordagem quantitativa, de cunho exploratório, sendo coletados dados primários por meio da aplicação de questionários via plataforma online. Assim, foram realizados dois levantamentos quantitativos (surveys). 0 procedimento metodológico e o instrumento de pesquisa foram os mesmos em ambos os casos, bem como a composição das amostras, não probabilísticas e selecionadas por conveniência.

0 primeiro levantamento $(n=316)$, mais geral, analisou três diferentes produtos, que expõem o mesmo selo verde, em conjunto. Já o segundo levantamento $(n=69)$ analisou-os isoladamente, comparando-os posteriormente. Foi especificada a seleção da amostra para alunos graduandos do curso de engenharia de produção de uma faculdade situada no interior de São Paulo, a fim de se conseguir homogeneidade entre os grupos. A distribuição foi aleatória entre os grupos.

Foi adotado como objeto de análise o selo verde 'I'm green', que certifica que o material usado na produção das embalagens é o Plástico Verde, composto de etanol de cana de açúcar, uma matériaprima renovável, enquanto os plásticos tradicionais utilizam matérias-primas de fonte fóssil, como petróleo. Os produtos foram escolhidos de forma a retratar diferentes categorias de produtos, bastante variadas, desde alimentação básica (arroz), limpeza (amaciante) até cuidados para animais de estimação (ração).

\section{Instrumento de Pesquisa}

0 questionário foi composto de cinco blocos principais. Antes de iniciar, havia um termo de consentimento, de participação livre e voluntária, com posterior publicação dos dados, o qual o respondente deveria assentir para dar continuidade. Logo depois, foi apresentada a imagem dos produtos que deveriam ser visualizados para posterior avaliação.
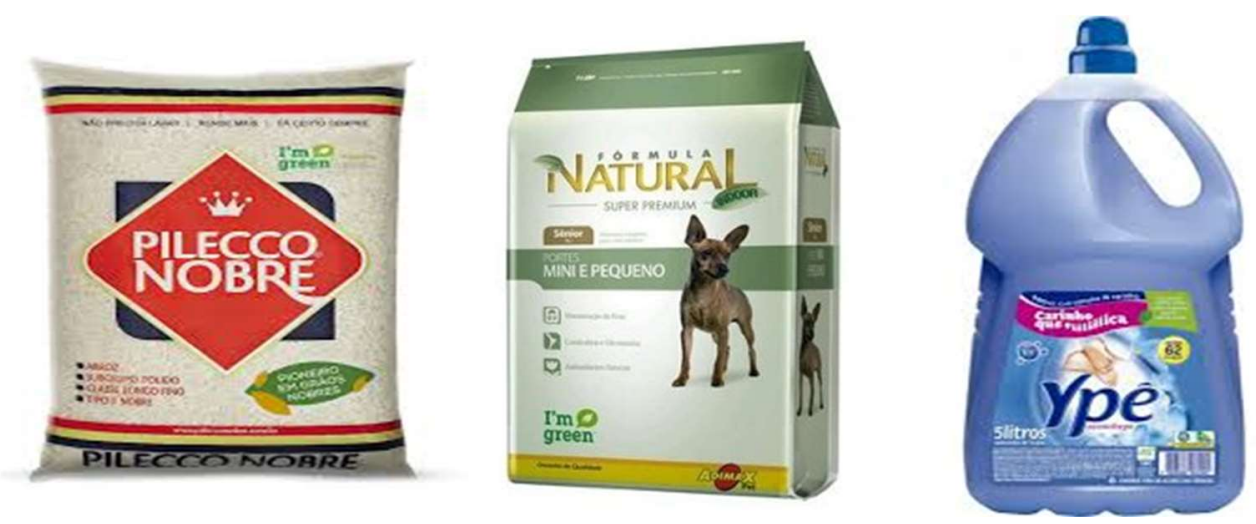

Figura 1. Ilustração dos produtos com o selo verde 'I'm green' Fonte: Braskem (2019).

Em primeiro lugar, foram apresentadas quatro questões para a avaliação dos produtos, de maneira geral. As duas primeiras questões eram fechadas, dicotômicas, indagando-se se o participante já tinha visto esses produtos antes e se já os havia comprado. Já a terceira questão, aberta, referiu-se a uma evocação livre de dois atributos que se relacionariam aos produtos. Na quarta questão, por meio de uma escala, foi analisada a avaliação de seis atributos acerca dos produtos exibidos: qualidade, custobenefício, imagem positiva, ecologicamente correta, responsabilidade ambiental e intenção de 
compra/consumo. Esses atributos foram apresentados de forma randômica a cada respondente, que deveria atribuir seu nível de concordância, de 0 a 10.

Em um segundo momento, foram apresentadas duas questões sobre o selo verde, especificamente. Sendo assim, a primeira questão, dicotômica, inqueriu se o participante lembrava de ter visto algum selo ou certificação nos produtos mostrados. Já a segunda questão consistiu em uma evocação forçada, na qual o respondente deveria dizer o nome ou a marca do selo/certificação.

Em terceiro lugar, foi exposta a imagem do selo verde 'I'm green', solicitando-se que o respondente atribuísse seu nível de concordância a seis assertivas acerca do selo em questão. Essas assertivas também foram apresentadas de forma randômica a cada respondente, em uma escala de 0 a 10.

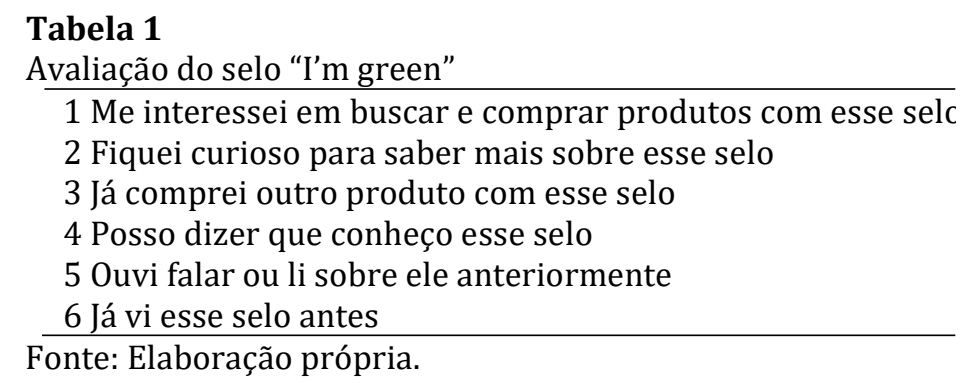

Logo após, foi exibida uma escala de avaliação acerca da prática de selos verdes, utilizada por Andreoli, Lima e Prearo (2017). Essa escala é composta de seis assertivas, para cada qual o participante deveria atribuir seu nível de concordância, de 0 a 10. Essas assertivas também foram apresentadas de forma randômica.

Tabela 2

Escala de avaliação de selos verdes

1 Eu preferiria comprar produtos que tivessem selos verdes, ao invés de comprar produtos similares sem esses selos

2 Acredito que os consumidores sempre reparam nos selos verdes dos produtos

3 Eu estaria disposto a pagar um pouco mais por produtos que tivessem selos verdes, ao invés de

Comprar similares mais baratos sem esses selos

4 Os selos verdes são uma certificação bastante confiável em relação à atuação das organizações

5 É impossível confundir ou mesmo enganar os consumidores com selos verdes falsos

6 A grande maioria dos consumidores entende o que os selos verdes significam

Fonte: Andreoli, Lima e Prearo (2017).

Por fim, havia o perfil do respondente, com a identificação do sexo, idade e renda familiar mensal. 0 questionário passou por um pré-teste conceitual junto a um júri de especialistas, formado por dois profissionais formados e atuantes na área mercadológica, tanto acadêmica quanto empresarialmente. Somente após isso, o questionário foi considerado apto para aplicação.

\section{Técnicas de Análise de Dados}

Foram utilizadas algumas técnicas de análise de dados. Em primeiro lugar, foi realizada a estatística descritiva básica. No caso das escalas, foram rodadas Análises Fatoriais Exploratórias. De forma complementar, também o teste de correlação paramétrico de Pearson foi utilizado. Para o segundo levantamento, possíveis diferenças entre os grupos foram verificadas, adotando-se o teste estatístico paramétrico ANOVA de um fator.

\section{APRESENTAÇÃO E ANÁLISE DE DADOS}

A seguir, são apresentados e analisados os dados de ambos os levantamentos, respectivamente. 


\section{Primeiro Levantamento}

A amostra $(n=316)$ foi composta por uma maioria de respondentes do gênero feminino $(56,8 \%)$, com baixa renda $(54,7 \%$ até $R \$ 2.900$, seguido de $30,1 \%$ entre $R \$ 2.900$ e $R \$ 7.250)$ e idade média de 34 anos (variando entre 15 e 77). 0 tempo médio de resposta foi de quatro minutos.

\section{Avaliação dos produtos}

Em um primeiro momento, foi indagado se os respondentes já tinham visto os produtos exibidos antes e se já o tinham comprado. As respostas indicam um conhecimento e consumo prévio acerca deles, com $77 \%$ que já os viram e 71,2\% que inclusive já os adquiriram. Ainda, foi analisada a avaliação de seis atributos acerca dos produtos dispostos, por meio de uma escala. Realizou-se uma análise fatorial, cujos resultados atendem aos pressupostos de consistência, obtendo-se um KMO de 0,912 (p=0,000), com MSA de todas as variáveis $(>0,88)$ e comunalidades $(>0,71)$ acima do proposto por Hair etl al $(2005)$. Ressalta-se que o modelo obteve $81,7 \%$ da variância total explicada. Assim, juntando esses atributos em uma escala de avaliação geral (alpha de Cronbach de 0,955 ), verificou-se uma tendência positiva, com uma média de 6,5, indicando uma boa avaliação dos produtos.

Analisando os atributos, separadamente, todas as assertivas tiveram respostas que variaram de 0 a 10, mas médias acima do ponto intermediário, e a maioria das respostas na nota 10 (moda). 0 atributo mais bem avaliado foi o de Qualidade (com média 7), seguido de Imagem Positiva, com média 6,8. Em terceiro lugar, destacou-se o aspecto Intenção de compra, com média 6,7. Em seguida, vieram os atributos ecologicamente correto e Responsabilidade ambiental, ambos com média 6,2. Por fim, ficou o atributo Custo-benefício, com média 5,9. Ou seja, de maneira geral, os produtos foram bem avaliados pelos respondentes, inclusive acerca dos atributos ambientais, ressaltando a importância dos apelos verdes como diferencial competitivo (Lopes \& Pacagnan, 2014; Guimares, Viana \& Costa, 2015).

\section{Avaliação do selo verde}

Em um segundo momento, questionando sobre o selo verde 'I'm green', especificamente, apenas $37,8 \%$ dos respondentes alegaram lembrar de tê-lo visto anteriormente, o que já mostra a disparidade em relação à percepção dos produtos e a do selo de fato. Quando solicitado que eles de fato evocassem qual era o selo apresentado, apenas 15,8\% dos participantes conseguiram evocar corretamente, bem como $1 \%$ se aproximou da resposta correta (como só 'green', incompletamente). Tal resultado evidencia a baixa capacidade dos respondentes de captar e perceber o selo, o que pode gerar questionamentos acerca de sua eficácia enquanto diferencial competitivo. Tal questionamento também já foi levantado pela literatura anterior (Andreoli, Lima \& Prearo, 2017).

Após a apresentação do selo em questão, foi solicitada uma avaliação dele. Realizou-se uma análise fatorial, cujos resultados atendem aos pressupostos de consistência, obtendo-se um KMO de $0,861(\mathrm{p}=0,000)$, com MSA de todas as variáveis $(>0,72)$ e comunalidades $(>0,82)$ acima do proposto por Hair etl al (2005). Ressalta-se que o modelo obteve 88,5\% da variância total explicada, com a composição de dois fatores. O primeiro mais expressivo (58,9\% da variância), denominado de conhecimento prévio (alpha de Cronbach de 0,964), agrupou as quatro primeiras assertivas, que mostrou uma tendência de avaliação desfavorável (média 4,5). Enquanto que o segundo (29,6\%), titulado de comportamento futuro (alpha de Cronbach de 0,794), com as demais duas assertivas, por outro lado, apresentou uma tendência de avaliação favorável (média 7). Assim, ainda que os respondentes pareçam não ter conhecimento prévio acerca do selo em questão, mostraram-se dispostos a considerá-lo em momentos futuros de decisão, ressaltando a possibilidade da prática de potencialmente agregador valor competitivo à organização.

Novamente, todas as assertivas tiveram respostas que variaram de 0 a 10, mas com oscilações em relação às médias e modas. Os atributos mais bem avaliados foram os de comportamento futuro, de curiosidade para saber mais (média 7,2) e de interesse em buscar e comprar produtos com ele (média 6,7). Em seguida, vieram os atributos de conhecimento prévio, com avaliação desfavorável, tais como já ter visto antes (média 4,6), já ter ouvido ou lido (médias 4,5) e conhece-lo (média 4,4). Tais resultados reforçam que o conhecimento prévio dos respondentes acerca do selo parece ser pouco, mas, por outro lado, a disposição para se engajar em comportamento futuros em relação a ele se mostra favorável. 
Em seguida, junto a uma breve explicação acerca da prática dos selos verdes, foi disposta outra avaliação acerca da prática de selos verdes. Todas as assertivas variaram suas respostas entre 0 e 10 . Assim, melhor resultado foi encontrado na assertiva de preferência em relação aos produtos com selos verdes (média 7), seguida das que os consumidores reparam nestes selos e que eles são uma certificação confiável, ambas com médias 5,8. Por outro lado, com avaliações desfavoráveis, ficaram as demais assertivas, de que é impossível confundir os consumidores com selos verdes falsos, de que os consumidores entendem o que os selos verdes significam e que sempre reparam neles. Por fim, na avaliação geral, a média ficou próxima ao ponto intermediário, o que pode indicar certa ambiguidade dos consumidores em relação à prática de selos verdes: por um lado, boa avaliação de preferência, confiabilidade e disposição a pagar; do outro, avaliação ruim sobre reparar, saber o significado e possibilidade de confusão/engano.

\section{Tabela 3}

Escala de avaliação de selos verdes com médias

\begin{tabular}{l|c}
\hline & Média \\
\hline 1 Eu preferiria comprar produtos que tivessem selos verdes, ao invés de comprar produtos & 7,0 \\
similares sem esses selos & 3,5 \\
2 Acredito que os consumidores sempre reparam nos selos verdes dos produtos & 5,8 \\
3 Eu estaria disposto a pagar um pouco mais por produtos que tivessem selos verdes, ao invés de & \\
comprar similares mais baratos sem esses selos & 5,8 \\
4 Os selos verdes são uma certificação bastante confiável em relação à atuação das organizações \\
É impossível confundir ou mesmo enganar os consumidores com selos verdes falsos & 4,6 \\
6 A grande maioria dos consumidores entende o que os selos verdes significam & 3,7 \\
Avaliação geral & 5,1 \\
\hline
\end{tabular}

Fonte: Elaboração própria.

Como fechamento da discussão, observou-se uma boa avaliação dos produtos por parte dos respondentes, inclusive acerca dos atributos ambientais, o que contribui para reforçar a importância dos apelos verdes como diferencial competitivo (Lopes \& Pacagnan, 2014; Guimarães, Viana \& Costa, 2015). Entretanto, por outro lado, também foi visualizada uma baixa capacidade dos respondentes de perceber o selo de fato, e, mais ainda, de evocá-lo, suscitando questionamentos sobre a eficácia dessa prática (Andreoli, Lima \& Prearo, 2018; Andreoli \& Batista, 2019).

Acerca da prática de selos verdes, pode-se dizer que a opinião dos respondentes se mostrou positiva. Primeiro, sobre o selo em questão, teve-se pouco conhecimento prévio, mas boa intenção de comportamento futuro, com disposição a considera-lo em um momento de decisão, reforçando a vantagem competitiva capaz de agregar (Lopes \& Pacagnan, 2014; Guimarães, Viana \& Costa, 2015). Já na opinião acerca da prática de selos verdes em geral, as avaliações variaram, em um sentido semelhante à métrica anterior, ou seja, desfavorável em relação às questões de reparar, saber o significado e possibilidade de confusão/engano, mas favorável acerca da preferência, confiabilidade e disposição a pagar mais. Assim, parece ainda haver certa ambiguidade m relação à prática de selos verdes, em que se reconhece sua importância e seu valor competitivo, mas os contrapõe à falta de conhecimento, postura e criticidade dos consumidores (Andreoli, Lima \& Prearo, 2018; Andreoli \& Batista, 2019).

\section{Tabela 4}

Quadro síntese dos resultados

\begin{tabular}{|c|c|c|c|c|c|}
\hline \multicolumn{2}{|c|}{ Avaliação do Produto } & \multicolumn{2}{|c|}{ Avaliação do Selo } & \multicolumn{2}{|c|}{ Avaliação Prática Selos } \\
\hline Conhecimento & $77 \%$ & Viram o selo & $37,8 \%$ & Preferência produtos & 7 \\
\hline Consumo & $71,5 \%$ & Evocação selo & $16,8 \%$ & Pagar mais por selo & 6 \\
\hline Geral & 6,5 & Conhecimento prévio & 4,5 & Certificação confiável & 6 \\
\hline Responsabilidade Ambiental & 6,2 & \multicolumn{2}{|c|}{ Ter visto antes $-4,6$} & Impossível confundir & 5 \\
\hline Imagem Positiva & 6,8 & \multicolumn{2}{|c|}{ Já ter ouvido/lido - 4,5 } & Consumidor entende & 4 \\
\hline Ecologicamente Correto & 6,2 & \multicolumn{2}{|c|}{ Conhecer o selo $-4,4$} & Consumidor repara & 4 \\
\hline
\end{tabular}




\begin{tabular}{c|ccccc}
\hline Qualidade & 7 & & $\begin{array}{c}\text { Comportamento } \\
\text { futuro }\end{array}$ & 7 \\
\hline Custo-benefício & 5,9 & & Curiosidade $-7,2$ \\
\hline Intenção de compra/consumo & 6,7 & & \multicolumn{2}{c}{ Interesse $-6,7$} \\
\hline
\end{tabular}

Fonte: Elaboração própria.

\section{Correlações}

Diversas variáveis se mostraram significativamente correlacionadas entre si. As medidas referentes ao produto se correlacionaram entre si, tais como já ter visto e já ter comprado, forte e positivamente $(R=0,806, p=0,000)$, e ambas com a avaliação geral, forte e negativamente $(R=-0,651$, $p=0,021$ e $R=-0,644, p=0,000$, respectivamente). Ou seja, isso indica que existe uma tendência entre ver e comprar o produto, bem como de avalia-lo mais favoravelmente.

No mesmo sentido, as medidas concernentes ao selo também se correlacionaram entre si, como os fatores de conhecimento prévio e comportamento futuro $(\mathrm{R}=0,468, \mathrm{p}=0,000)$, e ambas com a avaliação da prática de selos verdes ( $R=0,666, p=0,000$ e $R=0,574, p=0,000$, respectivamente), todas positivas. Assim, também se sugere uma tendência de saber sobre o selo e considerá-lo em momentos futuros de decisão, bem como de avaliar mais favoravelmente essa prática. Nesse sentido, parece ser o caminho mandatório uma maior divulgação dos selos verdes adotados pelas organizações, a fim de que tal prática seja primeiro percebida e, posteriormente, bem valorada pelo mercado consumidor. Ou seja, o conhecimento se mostra condição necessária para a real agregação de valor como diferencial competitivo (Andreoli, Lima \& Prearo, 2017).

Além disso, as métricas do produto e dos selos também apresentaram correlações, de maneiras diversas. Já ter visto e comprado os produtos, bem como tê-los avaliado bem, parece estar relacionado ao maior conhecimento prévio ( $\mathrm{R}=-0,377, \mathrm{p}=0,000, \mathrm{R}=-0,346, \mathrm{p}=0,000$ e $\mathrm{R}=0,504, \mathrm{p}=0,000)$ ) e comportamento futuro $(\mathrm{R}=-0,182, \mathrm{p}=0,000, \mathrm{R}=-0,217, \mathrm{p}=0,000$ e $\mathrm{R}=-0,200, \mathrm{p}=0,000)$, assim como a melhor avaliação da prática de selos verde $(R=-0,394, p=0,000)$, indicando uma certa sinergia entre os produtos e os selos verdes expostos neles.

\section{Segundo Levantamento}

Em um primeiro momento, buscou-se verificar eventuais diferenças nas reações dos consumidores acerca dos selos verdes dependendo do produto em que eram expostos. Desta forma, foram comparadas as respostas dos três produtos-alvo deste estudo: ração $(n=23)$, amaciante $(n=22)$ e arroz $(n=24)$. Nos três casos, a amostra foi composta por estudantes de engenharia, com grande maioria de respondentes do gênero masculino e de baixa renda pessoal mensal, com variação de idade entre 18 e 54 anos. Entretanto, nenhuma diferença significativa foi encontrada entre os três produtos, verificadas por meio da estatística paramétrica ANOVA de um fator. Apesar disso, algumas considerações podem ser feitas.

Referente à avaliação do produto, ainda que todos eles tenham sido avaliados favoravelmente, a ração foi a pior avaliada em todos os atributos, resultado em uma média de 6,4. 0 amaciante foi melhor avaliado em quatro atributos, ficando com a melhor média $(7,1)$, mas o arroz se mostrou melhor posicionado justamente em relação aos atributos verdes (ecologicamente correta e responsabilidade ambiental), com média geral de 6,7. Tais posições se repetiram em relação a já terem visto e/ou comprado esses produtos antes, com o amaciante melhor posicionado ( $86 \%$ e $48 \%$, respectivamente) e a ração pior (39,1\% e $22,7 \%$, respectivamente).

Relativo à avaliação específica do selo 'I'm green', as avaliações variaram entre desfavoráveis, intermediárias e favoráveis, com melhor julgamento no caso do amaciante (média de 5,1), seguido da ração $(4,9)$ e, por fim, o arroz $(4,6)$. No fator conhecimento prévio, as diferenças foram mais expressivas, com melhor avaliação da ração $(5,0)$, seguido do amaciante $(4,4)$ e depois arroz $(3,8)$, enquanto que sobre o comportamento futuro ficaram na mesma casa numérica, com melhor avaliação do amaciante $(6,8)$, e empate entre os demais $(6,1)$. Um pouco mais favoráveis, concernente à prática de selos verdes, em geral, amaciante respondeu pela melhor avaliação $(6,2)$, seguido da ração $(6,1)$ e do arroz $(5,7)$. 
Tabela 5

Resultados das avaliações dos três produtos

\begin{tabular}{|c|c|c|c|}
\hline & Ração & Amaciante & Arroz \\
\hline Já viu antes & $39,1 \%$ & $85,7 \%$ & $60,9 \%$ \\
\hline Já comprou antes & $22,7 \%$ & $47,6 \%$ & $45,8 \%$ \\
\hline 1.1 Qualidade & 6,4 & 7,7 & 6,7 \\
\hline 1.2 Custo-benefício & 5,8 & 6,7 & 6,3 \\
\hline 1.3 Imagem positiva & 6,7 & 7,7 & 6,9 \\
\hline 1.4 Ecologicamente & 6,7 & 6,7 & 7,1 \\
\hline 1.5 Responsabilidade & 6,4 & 6,8 & 7,2 \\
\hline 1.6 Intenção compra/consumo & 5,5 & 6,8 & 6,2 \\
\hline 1 Avaliação geral & 6,3 & 7,1 & 6,7 \\
\hline Viu o selo & $38,1 \%$ & $22,7 \%$ & $39,1 \%$ \\
\hline Sabe evocar o selo visto & $8,6 \%$ & $0 \%$ & $25 \%$ \\
\hline 2.1 Já vi esse selo antes & 5,1 & 4,9 & 3,8 \\
\hline 2.2 Ouvi falar ou li sobre ele anteriormente & 4,9 & 3,9 & 3,7 \\
\hline 2.3 Posso dizer que conheço esse selo & 4,7 & 4,3 & 3,3 \\
\hline 2.4 Já comprei outro produto com esse selo & 3,7 & 3,6 & 3,9 \\
\hline 2.5 Fiquei curioso para saber mais sobre esse selo & 6,6 & 7,5 & 6,4 \\
\hline 2.6 Me interessei em buscar e comprar produtos com esse selo & 5,6 & 6,2 & 5,8 \\
\hline 2 Avaliação Selo I'm green & 4,9 & 5,1 & 4,6 \\
\hline 2a Fator Conhecimento prévio & $\mathbf{5 , 0}$ & 4,4 & 3,8 \\
\hline 2b Fator Comportamento futuro & 6,1 & 6,8 & 6,1 \\
\hline $\begin{array}{r}\text { 3.1 A grande maioria dos consumidores entende o que os selos verdes } \\
\text { significam }\end{array}$ & 5,2 & 4,1 & 5,1 \\
\hline $\begin{array}{r}3.2 \text { Acredito que os consumidores sempre reparam nos selos verdes } \\
\text { dos produtos }\end{array}$ & 5,1 & 3,9 & 4,1 \\
\hline $\begin{array}{r}3.3 \text { Os selos verdes são uma certificação bastante confiável em } \\
\text { relação à atuação das organizações }\end{array}$ & 6,8 & 7,3 & 6,6 \\
\hline $\begin{array}{r}3.45 \text { É impossível confundir ou mesmo enganar os consumidores } \\
\text { com selos verdes falsos }\end{array}$ & 5,4 & 6,8 & 5,6 \\
\hline $\begin{array}{r}3.51 \text { Eu preferiria comprar produtos que tivessem selos verdes, ao } \\
\text { invés de comprar produtos similares sem esses selos }\end{array}$ & 7,2 & 8,2 & 7,3 \\
\hline $\begin{array}{r}3.63 \text { Eu estaria disposto a pagar um pouco mais por produtos } \\
\text { tivessem selos verdes, ao invés de comprar similares mais baratos sem } \\
\text { esses selos }\end{array}$ & 6,5 & 7,1 & 5,3 \\
\hline 3 Avaliação Prática de selos verdes & 6,1 & 6,2 & 5,7 \\
\hline
\end{tabular}

Fonte: Elaboração própria.

Assim, não foram encontradas diferenças nas avaliações dos consumidores em relação a produtos diferentes. Além disso, repetem-se os resultados do levantamento anterior, o que contribui para uma corroboração da discussão traçada. Novamente, foram observadas boas avaliações dos produtos, inclusive acerca dos atributos ambientais. Mas, por outro lado, também novamente foi visualizada uma baixíssima capacidade dos respondentes de percepção dos selos. Igualmente, sobre o selo 'I'm green', teve-se pouco conhecimento prévio, mas boa intenção de comportamento futuro. Também na avaliação da prática em geral, as avaliações foram desfavoráveis em relação às questões de reparar e saber o significado, novamente ilustrando a percepção de falta de conhecimento dos consumidores, mas favoráveis nas demais, em que se pontam os selos como importantes diferencias competitivos.

\section{CONSIDERAÇOES FINAIS}

0 trabalho teve como objetivo analisar a influência da prática de selos verdes no comportamento dos consumidores. Com isso, foi possível observar que a falta de consenso acerca dessa prática evidenciada pela literatura corrobora com o que se verifica perante os consumidores, que demonstraram clara ambiguidade concernente a ela. 
Por um lado, houve boa avaliação dos produtos que expõem o selo verde em suas embalagens, inclusive acerca dos atributos ambientais. Mas, por outro lado, não houve percepção nem retenção do selo por eles, que também indicaram pouco conhecimento prévio. Apesar disso, parece haver uma boa intenção de comportamento futuro, já que ajuízam os selos como importantes diferenciais competitivos capazes de influenciar em seus momentos de decisão de compra. Ainda, não houve diferenciação em relação ao produto expositor, mesmo se tratando de categorias diferentes.

Desta forma, o estudo demonstra que de fato há um valor agregado percebido pelo consumidor acerca da prática de selos verdes, o que corrobora com a literatura levantada acerca da importância do marketing verde e das vantagens dos selos verdes. Todavia, percebe-se que o próprio consumidor reconhece que seu papel acaba enfraquecendo ou influenciado desfavoravelmente essa prática, admitindo que ainda é pequena a parcela do mercado que de fato se mostra crítica e ambientalmente responsável. Em que pese isso, também foi declarada favorável intenção de engajamento em comportamentos futuros mais conscientes nesse sentido, novamente reforçando a prática verde como capaz de agregação de valor.

Nesse sentido, ressalta-se a necessidade de uma maior educação e conscientização do mercado consumidor acerca da problemática ambiental frente aos impactos do consumo. 0 consumidor, como elo final da cadeia produtiva e objeto-alvo das organizações, deve assumir seu papel de responsabilidade. A falta de criticidade e de auto percepção dos consumidores acerca disso já foram apontadas em estudos anteriores (Andreoli, Lima \& Prearo, 2017; Andreoli \& Batista, 2019; Andreoli \& Batista, 2020). Reforça-se que não se trata apenas de cobrar práticas mais ambientalmente responsáveis por partes das organizações, mas sim de realmente acompanhar a atuação do meio empresarial, informar-se sobre as práticas que estão sendo desenvolvidas e valorizar as ações corretas por meio da sua decisão de compra e consumo.

Como implicação gerencial, argumenta-se que as organizações que queiram adotar o marketing verde e se beneficiar da imagem verde perante o mercado devem levar o supracitado em conta. Isto é, será fundamental que as organizações aderentes se incubam de divulgar e esclarecer o consumidor acerca da importância da prática verde e de comportamentos de compra mais ecologicamente corretos.

Diante das limitações deste estudo, especialmente as resultantes das delimitações metodológicas, novas pesquisas são sugeridas para investigação da prática de selos verdes perante seu mercado consumidor. Parece contra intuitivo não haver diferenciação nas avaliações entre produtos tão distintos. Assim, recomenda-se que novos estudos se aprofundem nessa verificação, expandindo a gama de produtos analisados e comparados. Além disso, também selos verdes distintos podem ser contrastados, a fim de se verificar eventuais diferenças decorrentes disso.

\section{References}

Andreoli, T. P., \& Batista, L. L. (2019). Pareço verde logo sou? Uma análise das associações que os consumidores fazem após exposição a peças publicitarias com apelos verdes. RIMAR - Revista Interdisciplinar de Marketing, 9(2).

Andreoli, T. P., \& Batista, L. L. (2020). Possíveis Ações Regulatórias do Greenwashing e suas Diferentes Influências na Avaliação de Marca e no Julgamento dos Consumidores. Revista Brasileira de Marketing, 19(1), 29-52.

Andreoli, T. P., Lima, V. A., \& Minciotti, S. A. (2018). Marketing social e marketing societal: uma confusão teórica. CONTEXTUS - Revista Contemporânea de Economia e Gestão, 16(2).

Andreoli, T. P., Lima, V. A., \& Prearo, L. C. (2017). A (in)eficácia dos selos verdes sobre o comportamento dos consumidores. Revista Eletrônica de Ciência Administrativa, 16(1).

Andreoli, T.P., Crespo, A. \& Minciotti, S. A. (2017). What has been (short) written about greenwashing: a bibliometric research and a critical analysis of the articles found regarding this theme. Revista de Gestão Social e Ambiental, 11(2).

Araújo, M. A. (2013) Produtos ecológicos para uma sociedade sustentável. Disponível em: $<$ www.idhea.com.br $>$; Acesso em 21/05/2019. 
Bergel, E., Brandão, M. M., Freire, O. L. \& Bizárrias, F. S. (2015). Relação entre Marketing e RSAE nos Congressos da ANPAD: Estudo Bibliométrico de 1998-2012. Revista de Administração da UNIMEP, $13,(1), 189-219$.

BRASKEM. Disponível em: <https://www.braskem.com.br/Principal/catalogo-de-produtos?key=36>.; Acesso em 21/05/2019.

Campos, S. A. P., Palma, L. S., Neutzling, D. M., Zucatto, L. C., \& Slongo, L. A. (2013) A comunicação verde fala por si? Efeitos na identidade corporativa e propensão de compra. Revista Eletrônica de Ciência Administrativa, 12(2), 191-204.

Guimarães, C., Viana, L. S., \& Costa, P. H. S. (2015). Os desafios da consciência ambiental: o marketing verde em questão. Cadernos de Aulas do LEA - C@LEA, 4, 94-104.

Kotler, P. (1978) Marketing para organizações que não visam lucro. São Paulo: Atlas.

Lopes, V. N., \& Pacagnan, M. N. (2014). Marketing verde e práticas socioambientais nas indústrias do Paraná. Revista de Administração, 49(1), 116-128.

Mangini, E. R., Amaral, L. M., Conejero, M. A., \& Pires, C. S. (2020). Greenwashing Study and Consumers' Behavioral Intentions. Consumer Behavior Review, 4 (3), 229-244.

Miranda, C. M. C. \& Arruda, D. M. O. (2004) A evolução do pensamento de marketing: uma análise do corpo doutrinário acumulado no século XX. RIMAR - Revista Interdisciplinar de Marketing, 3(1), 40-57.

Morais, M. R. B., Giuliani, A. C., Farah, O. E. \& Spers, E. (2005). Marketing societal e marketing social: uma visão empresarial. Revista Ciências Administrativas, 11(2), 241-249.

POLIETILENO VERDE I'M GREEN ${ }^{T M}$ (PE VERDE I'M GREEN ${ }^{T M}$ ). I'm green. Disponivel em: $<$ http://plasticoverde.braskem.com.br/site.aspx/PE-Verde-Produtos-e-Inovacao $>;$ Acesso em 21/05/2019.

Schneider, G., \& Luce, F. B. (2014). Marketing Social: Abordagem histórica e desafios contemporâneos. REMARK, 13(3).

Silva, E. C., \& Minciotti, S. A. (2005). Marketing Ortodoxo, Societal e Social: As Diferentes Relações de Troca com a Sociedade. Revista Brasileira de Gestão de Negócios, 7(17), 15-22.

Silva, E. C., Minciotti, S. A., \& Romeiro, M. C. (2011). Marketing societal: uma contribuição para o crescimento sustentável das organizações. Revista de Administração da UFSM, 4(1), 19-38.

Wells, C. (2006) Rotulagem Ambiental. IN: Vilela Júnior, A., \& Demajorovic, J. (ORG). Modelos e ferramentas de gestão ambiental. Desafios para as organizações. $2^{\underline{a}}$ ed. São Paulo: Editora Senac são Paulo, 2006. 